Revista Iberoamericana, Vol. LXXIX, Núm. 242, Enero-Marzo 2013, 243-256

\title{
GENEALOGÍAS TRANSNACIONALES CENTROAMERICANAS: DE MÁXIMO SOTO HALL A FRANCISCO GOLDMAN
}

\author{
POR \\ Ana Patricia Rodríguez \\ University of Maryland, College Park
}

A fines del siglo xix y a principios del siglo xx José Martí(1853-1895), Rubén Darío (1867-1916) y el guatemalteco Máximo Soto Hall (1871-1944) viajaban por todo el mundo, ejerciendo cargos públicos a la vez que publicaban textos periodísticos y literarios por donde estuvieran. Como explica Julio Ramos en Desencuentros de la modernidad en América Latina: Literatura y política en el siglo XIX, el periodismo (en particular la producción de las crónicas) hacía posible que estos escritores modernos no sólo se profesionalizaran en el mercado internacional de las letras, sino que también produjeran nuevas redes de comunicación y otros espacios culturales y políticos a través de Norte, Centro y Sud América, el Caribe y Europa. Se podría decir que su escritura en conjunto era transnacional por virtud de su circulación a través de fronteras políticas, culturales y lingüísticas, y de su consolidación de comunidades imaginarias transculturales y transterritoriales, que, en su momento, Martí llamaría "Nuestra América” y que otros identificarían como configuraciones panamericanistas, interamericanas o hemisféricas en los siglos xx y xxi (Bauer 234-50).

En este trabajo me interesa explorar, en particular, la intertextualidad transnacional que se produce entre Guatemala y Nueva York a partir de lecturas de varios textos de José Martí ("La niña de Guatemala”), Máximo Soto Hall (La niña de Guatemala: El idilio trágico de José Martí y La sombra de la Casa Blanca) y Francisco Goldman (The Divine Husband o El esposo divino). Martí pasó un tiempo en Guatemala, entre 1877 y 1878, dejando huellas en la política, cultura y literatura de dicho país, partiendo posteriormente a Nueva York, en donde Soto Hall lo visitó en 1892 en uno de sus tantos viajes a Nueva York. ${ }^{1}$ En la década de 1990, el escritor guatemalteco-estadounidense

1 Soto Hall ejerce diversos cargos diplomáticos en nombre del gobierno guatemalteco y otros que lo llevan a pasar largos periodos de tiempo en Nueva York, Washington D.C. y otras ciudades capitalinas de América Latina. En la base de datos de la "Ellis Island Organization”, digitados en su página Web, se puede encontrar la lista de viajeros en la nave "Caracas" que había partido de La Guaira, Venezuela, a 
Francisco Goldman, motivado por sus lecturas de infancia del poema "La niña de Guatemala”, de Martí, retoma la historia de Martí en ambos lugares. El eje textual que comparten todos estos textos es el poema de Martí, "La niña de Guatemala", que alude a la supuesta historia de amor entre Martí y María García Granados, hija adolescente del ex-presidente de Guatemala, Miguel García Granados (1809-1878). Es ella la niña que “muere de amor” por José Martí, como lo cuenta la leyenda.

Tomando como punto de partida la estadía de Martí en Guatemala y su impacto discursivo en América Central, este trabajo ofrece una lectura genealógica provisional a manera de la genealogía foucaultiana que enlaza dichos textos de Martí, Soto Hall y Goldman, y que trae a luz la presencia centroamericana en los Estados Unidos (particularmente en Nueva York) en ciertos momentos históricos y discursivos precisos. A saber, los centroamericanos empiezan a llegar a ciudades de los Estados Unidos de Norteamérica en el siglo xix (ver Hamilton y Chinchilla; o Córdova) cuando la producción cafetalera industrial, las Reformas Liberales a servicio de la modernización de América Central, la construcción del Canal de Panamá y los conflictos políticos internos así como los factores económicos de expulsión y atracción (push-and-pull) abren la región al mundo y, en algunos casos, expulsan algunos sujetos nacionales fuera del territorio nacional, creando de tal manera las bases de la diáspora centroamericana actual. El flujo transnacional de productos, capital e inmigrantes en la economía global es un proceso que data desde el siglo xix en América Central. Las comunidades expatriadas en Nueva York, San Francisco y otros lugares dan constancia de los enclaves migratorios tempranos de centroamericanos en los Estados Unidos. Esos enclaves incipientes sirven de centros de atracción a los inmigrantes del siglo xIx y xx. Al seguir los pasos de Martí, Soto Hall y otros por sus recorridos en los Estados Unidos llegamos, pues, a las comunidades tempranas de centroamericanos y latinoamericanos en lugares como Tampa, Florida; San Francisco, California; y, por supuesto, Nueva York.

donde Soto Hall había llegado para fundar un nuevo periódico en 1920. Se documenta la entrada de un Máximo Soto Hall y su esposa Amy de Soto Hall al Puerto de Nueva York el 23 de diciembre de 1920. Detalles vitalicios lo identifican de tal manera: 49 años de edad; sexo masculino; casado; escritor por profesión; alfabeto en el idioma español; nacionalidad guatemalteca; "Spanish American” / castellano americano de raza; país y cuidad de procedencia, Guatemala / Ciudad de Guatemala; destino en los EE.UU., Nueva York. Se indica además que ha hecho viajes anteriores a los EE.UU., que se va a hospedar en el Endicott Hotel en Nueva York, que no es polígamo, anarquista, discapacitado o deforme, y que no ha sido deportado previamente. Más aún, su condición de salud mental y física es buena, mide 5 pies 9 pulgadas, tiene piel oscura, pelo café, ojos cafés, y no tiene otras señas. Se indica además que en esta visita Soto Hall y su esposa se quedarán seis meses en los Estados Unidos y en ningún momento serán cargos del estado.

$\begin{array}{llllll}\text { ISSN 2154-4794 (Electrónico) } & \text { Revista Iberoamericana, Vol. LXXIX, Núm. 242, Enero-Marzo 2013, }\end{array}$ 


\section{GENEALOGÍAS CENTROAMERICANAS}

A partir de las propuestas de Michel Foucault sobre la genealogía, en este trabajo se propone explorar o como diría Foucault "excavar" una genealogía de la presencia centroamericana transnacional en los Estados Unidos y, más aun, de los circuitos discursivos transnacionales centroamericanos a partir del siglo XIX -sin acudir a puntos de origen o figuras fundadoras-. Según la genealogía de Foucault, no hay puntos originarios, ni momentos fundadores ni historias generales o continuas, sino historias contingentes enlazadas tal vez por puntos de ruptura e irrupciones de eventos. A base de la propuesta genealógica de Foucault, en este proyecto no se trata de producir una cronología del transnacionalismo centroamericano, ya sea en el istmo o fuera de él, ni de escribir la historia de los centroamericanos en los Estados Unidos o su migración temprana al Norte. No se trata tampoco de escribir una historia de orígenes o historia general sino de investigar e interpretar eventos concretos de la transnacionalidad centroamericana. Se pregunta, en este trabajo, ¿cómo y en qué textos se empieza a notar la presencia centroamericana en los Estados Unidos fuera de una historia documentada de esta población? En su análisis de la construcción de lo centroamericano en los Estados Unidos, Arturo Arias nos recuerda que no sólo falta traer a la luz contemporánea la presencia centroamericana en los Estados Unidos, sino también sacarla de lo que él llama su "invisibilidad" impuesta (Arias 168-87). Aquí se busca la presencia centroamericana en los Estados Unidos por medio de las alusiones, los significantes y los textos de algunos escritores que, como veremos, forman un circuito discursivo que apunta a América Central y a los centroamericanos en los Estados Unidos.

Se ha propuesto al inicio de este trabajo que la genealogía de los circuitos centroamericanos transnacionales se puede rastrear hasta llegar al Nueva York del fin del siglo xIx y del inicio del siglo xx, tal y como lo indica Soto Hall en su libro La niña de Guatemala: El idilio trágico de José Martí y como es representado en su otra novela La sombra de la Casa Blanca, publicada en Buenos Aires en 1927, así como en la novela El esposo divino, de Francisco Goldman, publicada en Nueva York en 2004. Estos textos son escritos y publicados con casi cien años de distancia, sin aparente conexión genealógica más allá de ser producidos por escritores guatemaltecos en diferentes contextos históricos. Soto Hall nace en 1871, pasa una gran temporada en Costa Rica (donde se le considera parte del canon literario costarricense por su novela El problema) y ejerce cargos diplomáticos internacionales bajo el régimen del dictador Manuel Estrada Cabrera (1857-1923) hasta emigrar permanentemente a Buenos Aires en 1921. En Argentina ejerce una gran carrera literaria y periodística y vive en esa ciudad hasta su muerte en 1944, no sin pasar largos períodos viajando a través de América Latina, Europa y los Estados Unidos. Por otro lado, Goldman, de madre guatemalteca y padre judío-estadounidense, nace en Massachusetts en 1954 y vive actualmente en

\footnotetext{
Revista Iberoamericana, Vol. LXXIX, Núm. 242,
ISSN 0034-9631 (Impreso)
} 
los Estados Unidos y México; es periodista y escritor de textos literarios. Goldman ha escrito sobre temas y sujetos centroamericanos en sus novelas The Long Night of White Chickens (La noche larga de los pollos blancos), The Ordinary Seaman (Marinero raso), The Divine Husband (El divino esposo) y The Art of Political Murder (El arte del asesinato político).

En sus respectivas novelas, Goldman y Soto Hall escriben desde coyunturas transnacionales geográficas y discursivas que giran en torno al eje "Guatemala-Nueva York", como explica Goldman de su propio trabajo literario en una entrevista con Esther Allen. Más aún, Goldman y Soto Hall participan en un circuito comunicativo transnacional de fines de siglo (xIx y xx) que conecta Guatemala con Nueva York, como lo había hecho anteriormente José Martí en su gira por Guatemala en 1877 y 1878. En Nueva York Martí escribió su poema más reconocido, “La niña de Guatemala”, ciudad en la que vivió exiliado por más de dieciséis años hasta su muerte en 1895. Soto Hall así como Goldman establecen conexiones especiales con Martí, ya sean vivenciales o intertextuales. Por un lado, Soto Hall de niño conoció a Martí cuando éste visitaba las tertulias de la madre de Soto Hall en la Ciudad de Guatemala en 1878 (Rodríguez Beteta xxx-xxxii) y en 1942, poco antes de su muerte, publicó su memoria de Martí, La niña de Guatemala: El idilio trágico de José Martí.

José Martí, poeta americano en Guatemala

El circuito discursivo transnacional que forjaron Martí, Darío, Soto Hall y otros puso en contacto, por la vía virtual o textual, los centros cosmopolitas de México, Buenos Aires, París, Nueva York y las zonas urbanas de América Central. Nos cuenta Soto Hall en La niña de Guatemala: El idilio trágico de José Martí, por ejemplo, que en 1877 Martí llegó a la Ciudad de Guatemala para quedarse un tiempo, y que en 1892 el mismo Soto Hall lo visitó en Nueva York poco antes del retorno de Martí a Cuba en 1895. "Estaba Martí, en aquel entonces [1892], entregado de lleno con toda la vehemencia de su alma pasional a las actividades revolucionarias" (Soto Hall, Niña 49). Pero mucho antes de eso, en 1877, el joven Martí se presentaba a la inteligentsia guatemalteca que lo invita inmediatamente a integrarse a la Sociedad "El Porvenir", cuya labor principal era fomentar la vida intelectual de la nación y ponerla al día con la cultura cosmopolita. Además de ser elegido vicepresidente de "El Porvenir", Martí fue puesto a cargo de fundar la Revista Guatemalteca - "una gran revista literaria, científica y de información, con el principal fin de dar a conocer a Guatemala en el exterior” (Soto Hall, Niña 61)-.

En su libro, Soto Hall cita un artículo periodístico contemporáneo que anuncia el proyecto (trans)nacional que va a titular Martí:

José Martí ha[bía] llegado a un país de rica fauna, de pintoresca flora, de majestuosos y profundos ríos, de árboles que elevan sus altas copas hasta besar con ellas la silueta

Revista Iberoamericana, Vol. LXXIX, Núm. 242, Enero-Marzo 2013, $243-256$
ISSN 2154-4794 (Electrónico) 
de las nubes, de tierra feracísima, en cuyas entrañas se opera la gestión del oro y sobre cuya superficie se levanta la caña de azúcar y el cafeto; ha estudiado con empeño y, más aún, con cariño, nuestros elementos y nuestras necesidades y ha comprendido que de muy poco sirve que nuestra patria dé pasos avanzados en la senda del progreso, si estos pasos no resuenan más allá de nuestras fronteras; que de muy poco sirve que la naturaleza nos haya dotado con tan pródiga mano si todos nuestros gérmenes de vida permanecen ocultos e inexplotados en el seno de la tierra. Por eso Martí se propone dar a luz un nuevo periódico, con el laudable y generoso pensamiento de exhibir a nuestro país y hacerlo conocer por las naciones extranjeras. (Soto Hall, Niña 62)

Mientras estuviera en Guatemala Martí no sólo daría a conocer Guatemala al mundo, ponerla en el mapa mundial por decirlo así, sino que también, como explica Soto Hall, Martí, por medio de sus amplios conocimientos y conexiones transcontinentales, traería el mundo a Guatemala. Más aún, explica Soto Hall, los guatemaltecos “[...] necesitamos estar al tanto del movimiento intelectual americano y europeo; anhelamos escuchar las últimas palabras de la civilización. Martí se propone llenar con su periódico, en cuanto le sea posible, esta necesidad cuya satisfacción reclama con imperio nuestro modo de ser” (Niña 63). Martí y su Revista Guatemalteca servirían para cosmopolitizar y civilizar a Guatemala y para hacerle una "infusión" cultural y civilizadora, como diría Soto Hall (Niña 63). ${ }^{2}$

A los veinticuatro años el joven cubano exiliado en Guatemala sería acogido por la sociedad guatemalteca que lo renombraba "Doctor Torrente" (59) porque así como le salían las palabras se ganaban la admiración de muchos de la ciudad letrada guatemalteca. Se le abrían las puertas a todas las casas adineradas y los círculos intelectuales de Guatemala, inclusive las tertulias literarias de la madre de Soto Hall [Guadalupe Hall Lara de Soto] y la casa propia de los García Granados en donde Martí cortejaba a una de las hijas de la familia mientras estaba ya comprometido con otra mujer en México. El encuentro entre Martí y María García Granados daría fruto al famoso poema necrológico de Martí, en que se dice que "la niña de Guatemala":

...Ella dio al desmemoriado

Una almohadilla de olor:

El volvió, volvió casado:

Ella se murió de amor.

2 En su tesis de maestría presentada a la Universidad de San Carlos de Guatemala, titulada El problema social del indio (1923), Miguel Ángel Asturias a su manera propone, entre otras cosas, el aprendizaje del castellano, la aculturación de tradiciones hispánicas u occidentales y la inmigración alemana y estadounidense racialmente blanca como "limpieza racial” e "infusión” civilizadora. En el fondo las propuestas de Asturias y Soto Hall no están muy lejos.

ISSN 0034-9631 (Impreso) 
...Ella, por volverlo a ver, Salió a verlo al mirador: El volvió con su mujer: Ella se murió de amor.

\section{$[\ldots]$}

...Se entró de tarde en el río, La sacó muerta el doctor: Dicen que murió de frío: Yo sé que murió de amor. (Martí, “La niña de Guatemala”)

En su versión de la historia de "la niña de Guatemala”, Soto Hall se aprovechará más aún del romance del idilio fatal y del mito de Martí en Guatemala para narrar su propia relación íntima con el poeta cubano. En el capítulo "José Martí en mi casa”, Soto Hall habla de su hermano mayor, el doctor Marco Aurelio Soto, quien fue presidente de Honduras, y de cómo el día que llegó Martí a su casa por primera vez consagró al joven Soto Hall como un niño que "promete mucho", diciéndole: "Su padre fue un grande hombre y su hermano lo es también. Está Ud. obligado a no ser menos que ellos" (Niña 85). De tal manera Soto Hall establece un (patri)linaje afectivo, intelectual y discursivo con el poeta que informará gran parte de su producción literaria, especialmente sus novelas antiimperialistas El problema y La sombra de Casa Blanca. En otro texto, Revelaciones íntimas de Rubén Darío, Soto Hall contará cómo, en 1914, el dictador de Guatemala, Manuel Estrada Cabrera, lo escogió a él para viajar a Nueva York en busca de Rubén Darío, pagarle sus deudas y a acompañarlo de regreso a Centroamérica poco antes de la muerte de Darío en 1916. Pareciera que en estos textos Soto Hall se presenta como mediador entre los más grandes escritores de su tiempo y como puente entre formas discursivas que van del Romanticismo y Modernismo hasta el Realismo social que trazan sus propias novelas, poesía, biografías y otros textos.

En su memoria, La niña de Guatemala: El idilio trágico de José Martí, Soto Hall menciona brevemente a María García Granados, quien muere, como dice el poema, poco después de que José Martí regresara a Guatemala de México, ya casado con su prometida Carmen Zayas Bazán. Según Soto Hall la muerte de la niña de Guatemala figura en Martí como un "inconsciente pecado" de dejarse amar cuando éste estaba destinado solamente a "la causa de Cuba" $(129,125)$. El texto de Soto Hall, en realidad, no es un relato de los amoríos de Martí ni de la vida de María García Granados, de quien al fin y al cabo se sabe tan poco. Gran parte del texto de Soto Hall se dedica, sin embargo, a describir el momento histórico nacional que atestigua Martí en Guatemala -el gobierno

ISSN 0034-9631 (Impreso) 
liberal reformista del General y Presidente Justo Rufino Barrios (1835-1885), la lucha contra los oligarcas conservadores, la emigración de disidentes políticos guatemaltecos y la solidaridad que presta Guatemala a la causa independentista cubana pese a la total falta de solidaridad con los marginados e indígenas de Guatemala que desaparecen del recuento histórico de Soto Hall. Según Soto Hall, "En cuanto a Martí no quedó menos bien impresionado [de Guatemala] y así lo oí de sus propios labios, mucho más tarde, cuando le visité en Nueva York” (95).

MÁximo Soto Hall, embajador CULtURAl PANAMERICANISTA

Soto Hall fue un escritor transnacional de descendencia británico-guatemalteca, de familia acomodada. Su hermano mayor, Marco Aurelio Soto, fue presidente de Honduras. Tenía lazos familiares con las estructuras de poder dentro y fuera de Centroamérica. Durante su vida, Soto Hall radicó en varias partes de América Latina, viajó por Europa y los EE.UU. y ejerció varias profesiones (Rodríguez Beteta xiii-xcvi). Entre ellas, Soto Hall fue escritor, periodista, funcionario estatal y diplomático internacional que asumió cargos importantes como "Ministro Plenipotenciario" de Guatemala en Costa Rica, El Salvador, Honduras, Panamá y Venezuela bajo el mandato del dictador Manual Estrada Cabrera. A partir de 1904 fue representante de Estrada Cabrera en la cumbre de presidentes centroamericanos; diputado en la Asamblea de Guatemala; agente financiero de Guatemala a cargo de la cancelación de la deuda externa en Washington, D.C.; delegado a la Conferencia Panamericana en Santiago de Chile en 1923, entre otras cosas. Durante su estadía en Costa Rica a fines del siglo xix fue director de la Biblioteca Nacional y participó en los debates intelectuales más candentes del país. Después de trasladarse a Buenos Aires, en donde vivió más de veinte años con su segunda esposa, Amy Miles, Soto Hall se dedica a escribir y publicar libros y a dirigir los Archivos Panamericanos de La Prensa que fundó en 1925. Para la sección panamericana él recopiló “un copioso material de libros y recortes, una biblioteca con los mejores y más útiles libros del continente, que ha de ir en aumento día a día y sobre todo, el gran archivo o fichero de recortes e información de toda clase sobre los países hispanoamericanos” (Rodríguez Beteta lxx-lxxi).

Según su biógrafo, Virgilio Rodríguez Beteta, Soto Hall escribió más de treinta y tres textos, entre ellos: El problema, Un Vistazo sobre Costa Rica en el Siglo XIX. 18001900, Revelaciones íntimas de Rubén Darío, Bernardo Monteagudo y José Cecilio del Valle: Dos grandes apóstoles del panamericanismo, La sombra de la Casa Blanca, Nicaragua y el imperialismo norteamericano, Del jardín de la leyenda, Monteagudo y el ideal panamericano, Herodías. Poema bíblico, Los Mayas, Instrucción Moral y Cívica, La divina reclusa (Sor Juana de Maldonado y Paz): Crónica novelada, El San Francisco de Asís Americano: Pedro de San José Bethencourt, e Historia de América.

\footnotetext{
Revista Iberoamericana, Vol. LXXIX, Núm. 242,
ISSN 0034-9631 (Impreso)
} 
Además, Soto Hall publicó números artículos en los más importantes periódicos y revistas del hemisferio (entre ellos, La Prensa y Pareceres de Buenos Aires y el Repertorio Americano de Costa Rica).

En su libro Ambassadors of Culture: The Transamerican Origins of Latino Writing, la investigadora Kirsten Silva Gruez identifica un número de intelectuales y escritores que ejercen cargos diplomáticos en los Estados Unidos a fines del siglo xix y a principios del xx. Estos “embajadores de cultura”, como los llama Silva Gruez, participan en proyectos intelectuales, culturales y políticos y, como en el caso de los exiliados de las primeras insurrecciones de Cuba a partir de 1868, incluyendo a Martí en su exilio en Nueva York, dirigen movimientos políticos desde el exilio. Estos exiliados establecen importantes redes sociales, políticas y de ayuda mutua en ciudades de los Estados Unidos como son Nueva York y Nueva Orleáns, sitios en los cuales surgen posteriormente grandes comunidades hispanas. Silva Gruez muestra que los “orígenes” de la cultura y la literatura latina estadounidense se encuentran en estos circuitos “transamericanos" o transnacionales. Dada su producción en diversos países de América Latina, su servicio diplomático y sus enlaces con otros escritores del hemisferio occidental, bien podría contarse Máximo Soto Hall entre los embajadores culturales procedentes de América Central.

La sombra de la Casa Blanca, de Soto Hall, es una de las primeras novelas que representa una presencia temprana de los centroamericanos en los Estados Unidos en el siglo xx. A mi parecer, no se ha recuperado otra novela anterior a la de Soto Hall que represente emigrantes y exiliados centroamericanos en Nueva York en los 1920. A su vez, el poeta nicaragüense José Coronel Urtecho (1906-1994) en su colección de ensayos titulado Rápido tránsito (al ritmo de Norteamérica) hace memoria de su estadía en San Francisco, California, en los 1920, y de sus viajes por Nueva York, Massachusetts y Nueva Orleáns en los 1940 tras las huellas de grandes escritores norteamericanos como Walt Whitman, Robert Frost, Robert Lowell, Mark Twain y William Thoreau. En sus viajes rastrea las tradiciones literarias que marcan la literatura mundial. A la vez, nos da pauta para contemplar, de nuevo, la presencia latina y centroamericana en los Estados Unidos, especialmente cuando cuenta que en el Nueva York de los 1940 había "habitantes procedentes de todos los rincones de la tierra, millones de judíos, italianos, puertorriqueños, centenares de miles de irlandeses y chinos, norteamericanos de todos los estados, latinoamericanos de las veinte repúblicas, emigrantes de todos los continentes y de las islas y aun de los pueblos más primitivos" (Coronel Urtecho 108; énfasis mío). Pero es en San Francisco, en "los gay 20”, que Coronel Urtecho se encuentra en casa entre la incipiente diáspora nicaragüense que llega huyendo de las dictaduras y la crisis política de su país (ver Córdova), todo lo cual forma la trama de la novela La sombra de la Casa Blanca, de Máximo Soto Hall.

La novela de Soto Hall comienza, pues, con un golpe de Estado en Nicaragua: el presidente liberal ha sido depuesto por el General Chorada del partido conservador. La

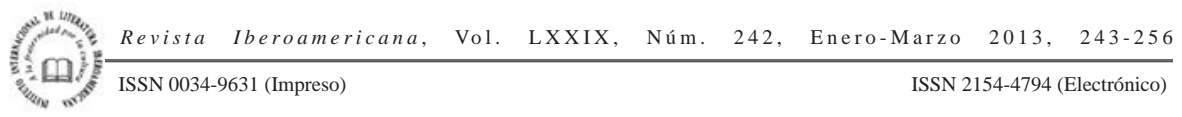


elite liberal representada por los personajes principales de la novela -Alberto Urzúa y su familia- se opone al nuevo gobierno pero no tiene manera de combatir la dictadura militar inicialmente apoyada por los Estados Unidos. Al morir el padre de Urzúa, el joven liberal se traslada a Nueva York con sus dos hermanas. El libro empieza con la llegada de Urzúa y sus hermanas a la bahía de Nueva York a bordo el vapor "Venezuela”, casi recreando o por lo menos invocando los viajes por barco al puerto de Nueva York que hacía Soto Hall en sus visitas diplomáticas. ${ }^{3}$

Bajo la mirada "soberbia" de la Estatua de la Libertad y ante el panorama de la metrópoli y los edificios que escalaban el cielo, los pasajeros eran sometidos a una rigurosa revisión de aduanas. En la novela se describe cómo los pasajeros tenían que:

[Llenar] los interminables requisitos que las leyes de los Estados Unidos imponen a los que quieren entrar al país. Vinieron sucesivamente las autoridades de la sanidad, de la inmigración, de la aduana, abrumando con sus cuestionarios y exigencias. Los extranjeros, sobre todo, eran sometidos a un riguroso examen que se intensificaba si por desgracia no podían explicarse en inglés. (Soto Hall, Sombra 7)

En las primeras páginas se describe además cómo las maletas y los baúles de los latinoamericanos eran registrados “con escrutadora insistencia” (9) y eran "víctimas de un empleado que a toda costa se empeñaba en encontrarles algún artículo de contrabando” (7). Por último, cuenta Urzúa que a sus hermanas y a él el agente de aduanas les preguntaba: “¿No alcojol [sic], no cocaína, no morfina?” (7). Por medio de estas líneas Soto Hall nos da a conocer la discriminación, el perfil racial (racial profiling) y las barreras lingüísticas que enfrentan los centroamericanos al llegar a Nueva York en los 1920. En el transcurso de tres años los hermanos Urzúa, sin embargo, se establecen en Nueva York, consiguen trabajos, estudian, se hacen de amistades latinoamericanas, se enamoran y se casan con norteamericanos, como lo había hecho el mismo Soto Hall con su esposa Amy Miles, originaria de San Francisco, California. En fin, los jóvenes se adaptan a su vida neoyorquina. Urzúa trabaja como representante de asuntos nicaragüenses en la sección de Centroamérica del Banco de Centro y Sud América, que, como veremos, jugará un papel importante en la vida personal de Urzúa y en la historia nacional de Nicaragua en los años veinte. La caída del joven Urzúa viene cuando se da cuenta de un complot para usarlo a él en una intervención en Nicaragua dirigida por el gerente del banco, el dueño de la compañía frutera, el ingeniero a cargo de diseñar el canal de Nicaragua, y un miembro del Departamento de Estado de los Estados Unidos.

La novela pone en juego los intereses territoriales y financieros en Nicaragua y el apoyo al gobierno golpista. Al final de la novela Urzúa se da cuenta de la farsa de su empleo en el Banco y del plan de Estados Unidos de apoyar la transición al poder del

3 Ver primera nota.

ISSN 0034-9631 (Impreso) 
presidente conservador Meses, de incrementar la deuda externa nacional a cambio de armas estadounidenses y de la eventual transferencia de poder a Alberto Urzúa mismo que hará el papel de presidente títere de Nicaragua. Como explica el texto, la restauración de los liberales al poder, o sea a Urzúa como futuro presidente, mostrará la neutralidad de los Estados Unidos en los asuntos exteriores y la instalación de un presidente “amigo” y endeudado a los Estados Unidos, garantizará el poder de los Estados Unidos en Nicaragua. Al darse cuenta de este complot, Urzúa decide unirse a la guerra de resistencia que está organizando un grupo de disidentes y aliados internacionales desde Nueva Orleáns, un centro importante de activismo hemisférico y de comunidades hispanas transnacionales, como explica Silva Gruez en Embajadores de cultura. El siguiente año, 1928, Soto Hall publicaría el libro Nicaragua y el imperialismo norteamericano que presenta un análisis de la Diplomacia del Dólar y la intervención estadounidense en Nicaragua.

En fin, la novela alude a la guerra revolucionaria de Augusto C. Sandino (aunque no lo nombre) a la cual Urzúa pareciera unirse. Escrita por un nacional guatemalteco radicado al final de su vida en Buenos Aires, de descendencia británica-guatemalteca, casado con una mujer estadounidense, La sombra de la Casa Blanca representa la política de los Estados Unidos en torno a Centroamérica en la década de los veinte, desde varias perspectivas, no sólo la de los nicaragüenses liberales, sino también la de una comunidad de expatriados y disidentes políticos radicados y organizándose en Nueva York y Nueva Orleáns. La sombra de la Casa Blanca así como la novela de Goldman revelan el mundo de las comunidades hispanas que forman la base de futuras inmigraciones a Nueva York y otros lugares. Lo interesante de la novela de Soto Hall es que representa el cuerpo diplomático que da origen a varias comunidades hispanas en Washington, D.C., y Nueva York.

FranCISCO GOLDMAN, ESCRITOR HEMISFÉRICO DE LAS AMÉRICAS

Como se ha mencionado anteriormente, el poema de amor de Martí a María García Granados inspira a Goldman a hacer investigaciones sobre la vida de Martí durante el año que éste pasó en Guatemala. Explica Goldman que habiendo leído el poema de Martí cuando aún era niño, él quería escribir una novela no precisamente histórica sobre Martí en Guatemala sino sobre el mundo del siglo xix cuando Martí llega a Guatemala. Son los años de las Reformas liberales de Justo Rufino Barrios (ver Burgess), la construcción del estado-nación liberal, el romanticismo de "la pequeña París" moderna y oligarca (como le llamaban a Guatemala), y el romance idílico de Martí con "la niña de Guatemala".

A partir de una rigurosa investigación de archivo en Guatemala y otros lugares tras las huellas de Martí y otros personajes históricos que le tomo más de siete años en terminar, Goldman produce una novela sobre un personaje ficticio llamado María de las Nieves Morán que también se enamora de Martí y por medio de quien vemos

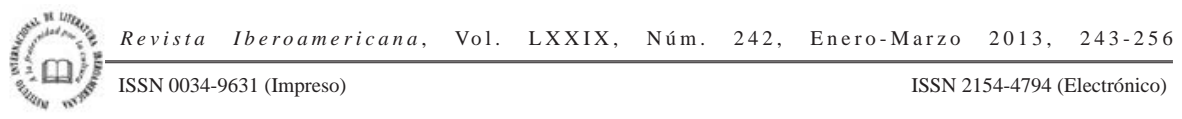


el mundo guatemalteco de fin de siglo. Bien cuenta Goldman que lo que proponía hacer con El divino esposo no era producir una novela histórica totalizadora sino una que novelizara la historia basada en una investigación profunda del periodo y de los personajes históricos, principalmente Martí, cuyo archivo transnacional es inmenso y se encuentra ubicado en bibliotecas, historias orales y otros espacios institucionales y no-institucionales en las Américas.

Tras estudiar profundamente el periodo histórico de Martí, Goldman construye su novela a partir de las lagunas e intersticios de la historia, o sea en los espacios ambiguos en donde no se conocen los detalles factibles de la vida de Martí, y él se convierte en materia de ficción así como la protagonista de la novela, María de las Nieves y su hija Matilde, quien pudo o no haber sido hija ilegítima de Martí. Éste es el gran enigma de la novela. Al pasar los años en la novela, los personajes principales, María de las Nieves, Francisca Aparicio (viuda de Justo Rufino Barrios) y Martí, se re-encuentran exiliados en Nueva York, siguiendo el circuito transnacional ya planteado aquí. A partir de este encuentro neoyorquino la novela de Goldman representa las comunidades latinas o centroamericanas en Nueva York, los otros neoyorquinos de quienes el archivo transamericano casi nunca habla. De tal manera la novela de Goldman es importante también porque nos ofrece una historia de las primeras comunidades centroamericanas a principios del siglo xx que emigran a ciudades como Nueva York y San Francisco, puntos centrales del transnacionalismo centroamericano.

\section{CONCLUSIÓN}

Para concluir, la novela La sombra de la Casa Blanca y la memoria La niña de Guatemala: El idilio trágico de José Martí, de Máximo Soto Hall, así como El esposo divino, de Francisco Goldman, se sitúan históricamente dentro de los flujos del capital transnacional que impacta las sociedades centroamericanas desde el siglo pasado hasta hoy en día. Los textos manifiestan cómo se introducen en Centroamérica las Reformas liberales, la explotación del monocultivo, las dictaduras militares, las intervenciones estadounidenses y los desplazamientos de poblaciones del campo a las ciudades o al exterior, entre otras ramificaciones de la modernización de Centroamérica. La sombra de la Casa Blanca, de Soto Hall, acude a los discursos panamericanistas de los 1920 mientras que la novela El divino esposo, de Goldman, es informada por los discursos hemisféricos o transamericanistas de finales del siglo xx, o mejor dicho, el discurso de "las Américas" tan popular en ciertos debates de los estudios americanos en los Estados Unidos. Una reseña de la novela de Goldman termina llamándola "the great novel of the Americas” (la gran novela de las Américas) y Goldman mismo ha dicho que quería crear una novela desde y para las Américas enlazando las visiones transamericanas o transnacionales del siglo xix y xxi (ver Allen). A partir de una lectura de los textos de

\footnotetext{
Revista Iberoamericana, Vol. LXXIX, Núm. 242, Enero-Marzo 2013, $243-256$
ISSN 2154-4794 (Electrónico)
} 
José Martí, Máximo Soto Hall y Francisco Goldman -todos producidos en diferentes contextos históricos y desde distintas reformulaciones de Nuestra América- logramos excavar una genealogía transnacional centroamericana que gira en torno a Guatemala y Nueva York. Como hemos visto, son los textos que hacen presencia y memoria de lo centroamericano en el mundo.

\section{BiBLIOGRAFÍA}

Allen, Esther. “Francisco Goldman”. Bomb 88 (2004). <http://bombsite.com/issues/88/ articles/2665>. 19 julio 2009.

Anderson, Benedict. Imagined Communities: Reflections on the Origin and Spread of Nacionalism. Londres: Verso, 1989.

Arias, Arturo. "Central American Americans: Invisibility, Power and Representation in the U.S. Latino World”. Latino Studies 1/1(2003): 168-87.

Asturias, Miguel Ángel. Guatemalan Sociology: The Social Problem of the Indian / Sociología guatemalteca: El problema social del indio. MaureenAhern, trad. Tempe: Arizona State University, Center for Latin American Studies, 1977.

Bauer, Ralph. "Hemispheric Studies”. PMLA 124/1(2009): 234-50.

Birnbaum, Robert. "Francisco Goldman: Author of The Divine Husband Converses with Robert Birnbaum”. 8 dic. 2004. <http://www.identitytheory.com/interviews/ birnbaum154.php>. 19 julio 2009.

Burgess, Paul. Justino Rufino Barrios: A Biography. Philadelphia: Dorance, 1926.

Córdova, Carlos B. The Salvadoran Americans. Westport: Greenwood, 2005.

Coronel Urtecho, José. Rápido tránsito (al ritmo de Norteamérica). Managua: Nueva Nicaragua, 1985.

Dirda, Michael. “The Divine Husband”. The Washington Post, 12 sept. 2004. <http:// www.washingtonpost.com/wp-dyn/articles/A10210-2004Sep9.html>.19julio 2009.

Ellis Island Foundation/Ellis Island Organization. “Amy Soto Hall”. Manifesto de barco. $<$ http://tinyurl.com/6da2ddp>. 14 sept. 2009.

“Amy Soto Hall”. Manifesto de barco. <http://tinyurl.com/6ajnjcp>. 14 sept. 2009.

Foucault, Michel. "Nietzche Genealogy, History”. The Foucault Reader. Paul Rabinow, ed. Nueva York: Panteón, 1984. 76-100.

Goldman, Francisco. The Art of Political Murder: Who Killed the Bishop? Nueva York: Grove, 2007.

The Divine Husband. Nueva York: Atlantic Monthly, 2004.

El esposo divino. Laura Emilia Pacheco, trad. Barcelona: Anagrama, 2008.

The Long Night of White Chickens. Nueva York: Grove, 1992.

The Ordinary Seaman. Nueva York: Grove, 1998.

Hamilton, Nora, y Norma Stoltz Chinchilla. "Central American Migration:A Framework for Análisis”. Challenging Fronteras: Structuring Latina and Latino Lives in the

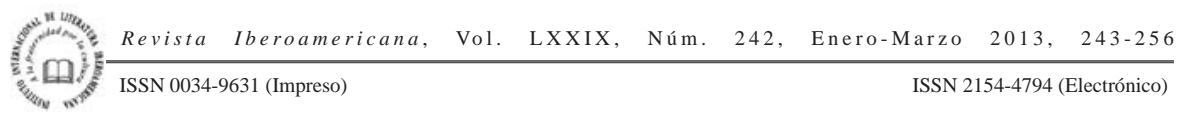


U.S. Mary Romero, Pierrette Hondagneu-Sotelo y Vilma Ortiz, eds. Londres: Routledge, 1997. 81-100.

Martí, José. “La niña de Guatemala”. Versos sencillos. 1891. <http://www.los-poetas. com/a/marti1.htm\#La\%20ni\%F1a\%20de\%20Guatemala>. 14 sept. 2009.

Mullan, John. "Zone of Anecdotes”. London Review of Books, 17 feb. 2005. <http:// www.lrb.co.uk/v27/n04/john-mullan/zone-of-anecdotes>. 19 julio 2009.

Ramos, Julio. Desencuentros de la modernidad en América Latina: Literatura y política en el siglo XIX. México: Fondo de Cultura Económica, 1989.

Rodríguez, Ana Patricia. Dividing the Isthmus: Central American Transnational Histories, Literatures and Cultures. Austin: U of Texas P, 2009.

Rodríguez Beteta, Virgilio. "Biografía del poeta, literato y periodista Máximo Soto Hall y prefacio a su obra Pedro de San José Bethencourt. Pedro de San José Bethencourt: El San Francisco de Asís americano". Guatemala: Ediciones del Gobierno de Guatemala, 1949.

Siegel, Lee. "Grand Illusions”. New York Times, 26 sept. 2004. <http://www.nytimes. com/2004/09/26/books/review/26SIEGELL.html>. 19 julio 2009.

Silva Gruez, Kirsten. Ambassadors of Culture: The Transamerican Origins of Latino Writing. Princeton: U of Princeton P, 2002.

Soto Hall, Máximo. Bernardo Menteagudo y José Cecilio del Valle: Dos grandes apóstoles del panamericanismo. Guatemala: Tipografía Sánchez y de Guise, 1926. Del jardín de la leyenda. Buenos Aires: El Ateneo, 1929.

La divina reclusa (Sor Juana de Maldonado y Paz): Crónica novelada. Santiago de Chile: Ercilla, 1938.

Herodías. Poema bíblico. Buenos Aires: Talleres Gráficos de Porter Hermanos, 1934.

Historia de América. Ricardo Levene, ed. Buenos Aires: Wm. Jackson, 1947. Instrucción moral y cívica. Guatemala: Gaubaud y Compañía, 1938.

Los mayas. Buenos Aires: Labor, 1937.

Monteagudo y el ideal panamericano. Buenos Aires: Tor/Ediciones Argentinas

Condor, 1933.

Nicaragua yel Imperialismo Norteamericano. Buenos Aires: Artes y Letras, 1928. La niña de Guatemala: El idilio trágico de José Martí. Guatemala: Tipografía Nacional, 1942.

El problema. San José: Editorial de la Universidad de Costa Rica, 1999. Revelaciones íntimas de Rubén Darío. Buenos Aires: El Ateneo, 1925.

El San Francisco de Asís Americano: Pedro de San José Bethencourt. Guatemala: Ediciones del Gobierno de Guatemala, 1945.

La sombra de la Casa Blanca. Buenos Aires: El Ateneo, 1927. Un vistazo sobre Costa Rica en el siglo XIX. 1800-1900. San José: Tipografía Nacional, 1901.

\footnotetext{
Revista Iberoamericana, Vol. LXXIX, Núm. 242,
ISSN 0034-9631 (Impreso)
} 
Villalon, Oscar. "Traversing Time and Terrain for a Grand Story of the Americas”. San Francisco Chronicle. 7 dic. 2004. <http://articles.sfgate.com/2004-12-07/ entertainment/17459321_1_divine-husband-francisco-goldman-new-novel>. 19 julio 2009.

ISSN 0034-9631 (Impreso) 